\title{
Metabolic engineering of Clostridium acetobutylicum for the industrial production of 1,3-propanediol from glycerol
}

\author{
María González-Pajuelo ${ }^{\mathrm{a}, 1}$, Isabelle Meynial-Salles ${ }^{\mathrm{b}, 1}$, Filipa Mendes ${ }^{\mathrm{a}}$, Jose \\ Carlos Andrade ${ }^{\mathrm{a}}$, Isabel Vasconcelos ${ }^{\mathrm{a}}$, Philippe Soucaille,* \\ ${ }^{a}$ Escola Superior Biotecnologia, Universidade Catolica Portuguesa, Rua Dr. António Bernardino de Almeida, 4200-072 Porto, Portugal \\ ${ }^{\mathrm{b}}$ CRT/CRITT-Bioindustries, INSA, 135 avenue de Rangueil, 31077 Toulouse cedex 4, France \\ ${ }^{\mathrm{c}}$ Laboratoire de Biotechnologie-Bioprocédés, UMR INSA/CNRS 5504, UMR INSA/INRA 792, INSA, 135 avenue de Rangueil, \\ 31077 Toulouse cedex 4, France
}

Keywords: 1; 3-propanediol; Glycerol; Clostridium acetobutylicum; Metabolic engineering; Vitamin $\mathrm{B}_{12}$-free biological process

\begin{abstract}
Clostridium butyricum is to our knowledge the best natural 1,3-propanediol producer from glycerol and the only microorganism identified so far to use a coenzyme $\mathrm{B}_{12}$-independent glycerol dehydratase. However, to develop an economical process of 1,3propanediol production, it would be necessary to improve the strain by a metabolic engineering approach. Unfortunately, no genetic tools are currently available for $C$. butyricum and all our efforts to develop them have been so far unsuccessful. To obtain a better "vitamin $\mathrm{B}_{12}$-free" biological process, we developed a metabolic engineering strategy with Clostridium acetobutylicum. The 1,3propanediol pathway from $C$. butyricum was introduced on a plasmid in several mutants of $C$. acetobutylicum altered in product formation. The DG1(pSPD5) recombinant strain was the most efficient strain and was further characterized from a physiological and biotechnological point of view. Chemostat cultures of this strain grown on glucose alone produced only acids (acetate, butyrate and lactate) and a high level of hydrogen. In contrast, when glycerol was metabolized in chemostat culture, 1,3-propanediol became the major product, the specific rate of acid formation decreased and a very low level of hydrogen was observed. In a fed-batch culture, the DG1(pSPD5) strain was able to produce 1,3-propanediol at a higher concentration (1104 mM) and productivity than the natural producer $C$. butyricum VPI 3266. Furthermore, this strain was also successfully used for very long term continuous production of 1,3-propanediol at high volumetric productivity $\left(3 \mathrm{~g} \mathrm{~L}^{-1} \mathrm{~h}^{-1}\right)$ and titer $(788 \mathrm{mM})$.
\end{abstract}

\section{Introduction}

For a long time, 1,3-propanediol (1,3-PD) has been considered a specialty chemical. However, the recent development of a new polyester called poly(propylene terephtalate), with unique properties for the fiber industry (Miller, 2000; Rudie, 2000), necessitates a drastic increase in the production of this chemical.

\footnotetext{
*Corresponding author.

E-mail address: soucaille@insa-toulouse.fr (P. Soucaille).

${ }^{1}$ María González-Pajuelo and Isabelle Meynial-Salles contributed equally to this work.
}

There are currently two processes for the chemical synthesis of 1,3-propanediol. Both of these processes produce toxic intermediates and require a reduction step under high hydrogen pressure (Sullivan, 1993). The biological production of 1,3-propanediol from glycerol was demonstrated for several bacterial strains, e.g., Lactobacillus brevis and buchnerii (Schütz and Radler, 1984; Sobolov and Smiley, 1959), Bacillus welchii (Humphreys, 1924), Citrobacter freundii, Klebsiella pneumoniae (Lin and Magasanik, 1960; Ruch et al., 1957; Streekstra et al., 1987), Clostridium pasteurianum (Luers et al., 1997) and Clostridium butyricum (Biebl et al., 1992; Heyndrickx et al., 1991; Saint-Amans et al., 
2001). Among those microorganisms, C. butyricum is to our knowledge the best "natural producer" both in terms of yield and titer of 1,3-propanediol produced (Saint-Amans et al., 1994). However, to develop an economical process of 1,3-propanediol production, it is necessary to further improve the process by a metabolic engineering approach on the strain. No genetic tools are currently available for C. butyricum and all our efforts to develop them have been so far unsuccessful. On the other hand, we recently characterized, from a biochemical (Saint-Amans et al., 2001) and a molecular point of view (Raynaud et al., 2003), the $\mathrm{B}_{12}$-independent pathway converting glycerol to 1,3-propanediol in $C$. butyricum. This work opens the possibility to convert other clostridia to 1,3-propanediol producers by the heterologous expression of the genes encoding the $\mathrm{B}_{12^{-}}$ independent 1,3-propanediol pathway. Among the clostridia, Clostridium acetobutylicum is a microorganism of choice as (i) it has already been used for the industrial production of solvent (Cornillot and Soucaille, 1996) and (ii) the genetic tools for gene knockout or gene over-expression are currently available (Mermelstein and Papoutsakis, 1993; Green et al., 1996). The objective of the present work is to develop a recombinant strain of $C$. acetobutylicum for the conversion of glycerol to 1,3-propanediol at higher titer and productivity and if possible higher yield than those obtained in C. butyricum. We succeeded for the first two objectives but we failed in the yield improvement due to the metabolic flexibility of $C$. acetobutylicum.

\section{Material and methods}

\section{Bacterial strains and plasmids}

All bacterial strains and plasmids used or derived from this study are listed in Table 1.

\section{DNA isolation and manipulation}

Plasmid DNA was extracted from Escherichia coli with the Qiaprep Kit (Qiagen, Courtaboeuf, France). DNA restriction enzymes, CIP enzyme and $\mathrm{T}_{4}$ DNA ligase were obtained from New England Biolabs (Beverly, Mass) or GIBCO/BRL (Life Technologies, Cergy Pontoise, France) and used according to the manufacturer's instructions. DNA fragments were purified from agarose gels with the QIAquick gel purification kit (Qiagen).

\section{Plasmids and genetic construction}

The $5.7 \mathrm{~kb}$ pTLH1 plasmid was digested with SalI restriction enzyme and treated with the CIP enzyme. The pSPD5 plasmid was digested with SalI and ClaI restriction enzymes. The $5.1 \mathrm{~kb}$ fragment obtained was gel purified and ligated to the SalI linearized pTLH1 vector to yield the $10.9 \mathrm{~kb}$ pTLP plasmid.

Prior to the transformation of $C$. acetobutylicum strains (ATCC 824, DG1 or ATCC 824 PJC4BK), pPSD5 and pTLP plasmids were methylated in vivo in E. coli ER2275 (pAN1) (Mermelstein and Papoutsakis, 1993), concentrated and desalted on a microcon 100 microconcentrator (Amicon, Inc., Beverly, Mass). Methylated plasmids DNA were used to transform $C$. acetobutylicum by electroporation as previously described (Mermelstein et al., 1992).

\section{Culture media}

E. coli strains were grown aerobically at $37^{\circ} \mathrm{C}$ in Luria-Bertani medium supplemented, when necessary with chloramphenicol $(30 \mu \mathrm{g} / \mathrm{ml})$ and ampicillin $(100 \mu \mathrm{g} /$ $\mathrm{ml})$ or tetracycline $(10 \mu \mathrm{g} / \mathrm{ml})$. The synthetic medium used for clostridia cultivations contained per liter of

Table 1

Bacterial strains and plasmids

\begin{tabular}{lll}
\hline Strain/Plasmid & Relevant characteristics ${ }^{\mathrm{a}}$ & Source/reference \\
\hline $\begin{array}{l}\text { C. acetobutylicum } \\
\text { ATCC 824 }\end{array}$ & Wild type & ATCC, Rockville, MD, USA \\
DG1 & Cured from pSOL1 & Nair (1995) \\
PJC4BK & $\mathrm{BK}^{-} \mathrm{MLS}^{\mathrm{r}}$ & Green et al. (1996) \\
E. coli & & New England Biolabs \\
ER 2275 & $\mathrm{recA}^{-} \mathrm{McrBC}^{-}$ & \\
Plasmids & & Mermelstein and Papoutsakis (1993) \\
pIMP1 & $\mathrm{MLS}^{\mathrm{r}}, \mathrm{Ap}^{\mathrm{r}}$, control plasmid & Mermelstein and Papoutsakis (1993) \\
pAN1 & $\mathrm{Cm}^{\mathrm{r}}, \Phi 3 \mathrm{TI}$ & Raynaud et al. (2003) \\
pSPD5 & $\mathrm{MLS}^{\mathrm{r}}, \mathrm{Ap}^{\mathrm{r}}$, dhaB1, dhaB2, dhaT \\
pTLH1 & $\mathrm{Tc}^{\mathrm{r}}, \mathrm{Ap}^{\mathrm{r}}$, control plasmid & Harris et al. (2000) \\
pTLP & $\mathrm{Tc}^{\mathrm{r}}, \mathrm{Ap}^{\mathrm{r}}$, dhaB1, dhaB2, dhaT & This study \\
\hline
\end{tabular}

${ }^{a}$ Abbreviations: BK: butyrate kinase; MLS ${ }^{\mathrm{r}}$ : macrolide, lincosamide, Streptogramin B resistance; RecA ${ }^{-}$: homologous recombination abolished; $\mathrm{McrBC}^{-}$: lacking methylcytosine-specific restriction system; $\mathrm{Ap}^{\mathrm{r}}$ : ampicillin resistance; $\mathrm{Cm}^{\mathrm{r}}$ : chloramphenicol resistance; $\mathrm{Tc}^{\mathrm{r}}$ tetracycline resistance; Ф3TI: $\Phi 3 T$ methylase. 
deionized water: glycerol, different amounts (10-120 g); $\mathrm{KH}_{2} \mathrm{PO}_{4}, 0.5 \mathrm{~g} ; \mathrm{K}_{2} \mathrm{HPO}_{4}, 0.5 \mathrm{~g} ; \mathrm{MgSO}_{4} \cdot 7 \mathrm{H}_{2} \mathrm{O}, 0.2 \mathrm{~g}$; $\mathrm{CoCl}_{2} \cdot 6 \mathrm{H}_{2} \mathrm{O}, 0.01 \mathrm{~g} ; \mathrm{FeSO}_{4} \cdot 7 \mathrm{H}_{2} \mathrm{O}, 0.01 \mathrm{~g} ;$ biotin, $0.04 \mathrm{mg}$; $p$-aminobenzoic acid, $8 \mathrm{mg}$; acetic acid, $2 \mathrm{~g}$. The $\mathrm{pH}$ of the medium was adjusted to 6.5 with $\mathrm{NH}_{4} \mathrm{OH}$ $6 \mathrm{~N}$. Commercial glycerol, a purified $87 \%(\mathrm{w} / \mathrm{v})$ grade glycerin, or raw glycerol, a by-product of biodiesel production process without any prior purification, were used as carbon source. Commercial glycerol was purchased from Riedel-de Haën (Germany). Raw glycerol, from the transesterification process for biodiesel production using rapeseed oil, was kindly supplied by Novance (Compiègne, France) and contained the following components (as provided by the supplier): glycerol, $65 \%(\mathrm{w} / \mathrm{v})$; sodium salts, less than $5 \%(\mathrm{w} / \mathrm{v})$; non-glycerol organic matter, less than $1 \%(\mathrm{w} / \mathrm{v})$; metals, less than $1000 \mathrm{ppm}$; heavy metals, less than $5 \mathrm{ppm}$. The feed medium for continuous cultures was the synthetic medium described above, without acetic acid, and with $0.028 \mathrm{~g} \mathrm{~L}^{-1}$ of $\mathrm{FeSO}_{4} \cdot 7 \mathrm{H}_{2} \mathrm{O}$ (instead of $0.01 \mathrm{~g} \mathrm{~L}^{-1}$ ), $1.5 \mathrm{~g} \mathrm{~L}^{-1}$ of $\mathrm{NH}_{4} \mathrm{Cl}$ and $1 \mathrm{ml}$ of $\mathrm{H}_{2} \mathrm{SO}_{4} 17.4 \mathrm{M}$; medium $\mathrm{pH}$ was not adjusted in this case. Media for $\mathrm{pH}$ regulated fed-batch cultures of C. acetobutylicum DG1 (pSPD5) was the same as described above, except that, instead of acetic acid, it contained $1.5 \mathrm{~g} \mathrm{~L}^{-1}$ of ammonium chloride and the amount of $\mathrm{FeSO}_{4} \cdot 7 \mathrm{H}_{2} \mathrm{O}$ was $0.028 \mathrm{~g} \mathrm{~L}^{-1}$. Yeast $\left(2 \mathrm{~g} \mathrm{~L}^{-1}\right)$ extract were also added to the medium. The initial glycerol concentration was $100 \mathrm{~g} \mathrm{~L}^{-1}$. The $\mathrm{pH}$ of the media was adjusted to 6.5 with $\mathrm{NH}_{4} \mathrm{OH} 14 \mathrm{~N}$.

\section{Continuous cultures conditions}

Continuous cultures were performed in a 2-L bioreactor Biostat MD (Braun, Melsungen, Germany), with a working volume of $1250 \mathrm{ml}$, and in a $600 \mathrm{ml}$ glass bioreactor, with a working volume of $500 \mathrm{ml}$. Cultures were stirred at $200 \mathrm{rpm}$, the temperature was set to $35^{\circ} \mathrm{C}$ and $\mathrm{pH}$ was maintained constant by automatic addition of $\mathrm{NH}_{4} \mathrm{OH} 6 \mathrm{~N}$. To create anaerobic conditions, the sterilized medium in the vessels was flushed with sterile $\mathrm{O}_{2}$-free nitrogen until room temperature was attained. A growing culture taken at the early exponential growth phase was used as inoculum $(10 \% \mathrm{v} / \mathrm{v})$. The cultures were first grown batchwise and continuous feeding was started once the exponential growth phase was reached. After sterilization, the feed medium was sparged with sterile $\mathrm{O}_{2}$-free nitrogen, until it reached room temperature. During the experiments, the feed medium was maintained under nitrogen at $30 \mathrm{mbar}$, to avoid $\mathrm{O}_{2}$ entry. All tubing were made of butyl rubber and the bioreactor gas outlet was protected with a pyrogallol arrangement (Vasconcelos et al., 1994).

\section{Fed-batch cultures conditions}

Fed-batch cultures were performed in a 5-L bioreactor Biostat B (Braun, Melsungen, Germany). After sterilization $\left(120^{\circ} \mathrm{C}, 20 \mathrm{~min}\right)$, the reactor containing $2 \mathrm{~L}$ of medium was degassed by sparging sterile $\mathrm{O}_{2}$-free nitrogen until room temperature was reached. A growing culture taken at the early exponential growth phase was used as inoculum $(10 \% \mathrm{v} / \mathrm{v})$. In batch cultures a good relationship between alkali and glycerol consumption was found and, therefore, the $\mathrm{pH}$-stat method was chosen to perform the fed-batch cultures. Feeding was started $21.5 \mathrm{~h}$ after inoculation: when $\mathrm{pH}$ reached a value below 6.5 , glycerol $(87 \% \mathrm{w} / \mathrm{v})$ was automatically added to the reactor by a Gilson peristaltic pump at the same time as alkali $\left(\mathrm{NH}_{4} \mathrm{OH} 14 \mathrm{~N}\right)$. Temperature was set at $35^{\circ} \mathrm{C}$. Stirring rate was set at $175 \mathrm{rpm}$.

\section{Analytical procedures}

Cell concentration was measured turbidimetrically, at $620 \mathrm{~nm}$, and correlated with cell dry weight determined directly. Glycerol, 1,3-propanediol, ethanol, butanol and acetic, butyric, formic and lactic acids concentrations were determined by HPLC analysis. Separation was performed on a Biorad Aminex ${ }^{\circledR}$ HPX-87H column $(300 \mathrm{~mm} \times 7.8 \mathrm{~mm})$ and detection was achieved by refractive index. Operating conditions were as follows: mobile phase, sulphuric acid $0.5 \mathrm{mM}$; flow rate, $0.5 \mathrm{ml} /$ min; temperature, $30^{\circ} \mathrm{C}$.

\section{Results}

\section{Engineering of $\mathrm{C}$. acetobutylicum for the production of 1,3-propanediol}

The conversion of glycerol to 1,3-propanediol in $C$. butyricum occurs in two steps catalyzed by the $\mathrm{B}_{12}$ independent glycerol dehydratase and the 1,3-propanediol dehydrogenase, consuming $1 \mathrm{~mol}$ of NADH. The pSPD5 plasmid (Raynaud et al., 2003) carrying the 1,3propanediol operon from $C$. butyricum and the pIMP1 as a control plasmid were introduced in $C$. acetobutylicum ATCC 824 and the DG1 mutant, which is cured from the pSOL1 megaplasmid and which is then unable to produce solvents and sporulate (Cornillot et al., 1997; Nair, 1995). The four recombinant strains were grown anaerobically in a synthetic medium without $\mathrm{pH}$ regulation and with glycerol as the sole carbon source. As expected, the two control strains ATCC 824 (pIMP1) and DG1 (pIMP1) were unable to grown on glycerol as they cannot re-oxidized the excess of NADH generated in glycerol catabolism. On the other hand, the ATCC 824 (pSPD5) and DG1 (pSPD5) recombinant strains expressing the 1,3-propanediol pathway from $C$. 
Table 2

Cultures of the three recombinant strains of C. acetobutylicum in a synthetic medium with $109 \mathrm{mM}$ glycerol and no pH regulation

\begin{tabular}{lllllll}
\hline \multirow{2}{*}{ Recombinant strains } & \multicolumn{2}{l}{ Fermentation products $(\mathrm{mM})$} & & Propanediol yield (mol/mol) \\
\cline { 2 - 6 } & 1,3-propanediol & Butyrate & Ethanol & Acetate & Butanol & \\
\hline ATCC (pSPD5) & 67 & 12 & 0 & 2.6 & 6 & 0.62 \\
DG1 (pSPD5) & 72 & 14 & 0 & 4 & 0 & 0.66 \\
PJC4BK (pTLP) & 58 & 0 & 1 & 6.9 & 16 & 0.54 \\
\hline
\end{tabular}

butyricum were able to grow on glycerol and produce 1,3-propanediol as the major product. While the DG1 (pSPD5) strain only produced acetate and butyrate as by-products, the ATCC 824 (pSPD5) also produced butanol, a molecule that needs $4 \mathrm{NADH}$ for its synthesis, and the 1,3-propanediol yield was lower for this strain $(0.62 \mathrm{~mol} / \mathrm{mol}$ versus $0.66 \mathrm{~mol} / \mathrm{mol})$ (Table 2).

In order to improve the yield of 1,3-propanediol production we wanted to introduce the 1,3-propanediol pathway into the $C$. acetobutylicum PJC4BK mutant (with a knockout of the $b k$ gene encoding the butyrate kinase) that produced very low amount of butyrate (Green et al., 1996). As the inactivation was done with the use of an erythromycin resistance gene we constructed the pTLP plasmid with the same 1,3-propanediol pathway as pSPD5 but with a tetracycline resistance gene in place of the erythromycin resistance gene. When grown on glycerol, C. acetobutylicum PJC4BK (pTLP) produces 1,3-propanediol as the main fermentation product and no butyrate; a relatively high amount of butanol was produced and consequently the 1,3propanediol yield $(0.54 \mathrm{~mol} / \mathrm{mol})$ was lower than the one observed for $C$. acetobutylicum DG1 (pSPD5) (Table 2). To reduce by-product formation and further improve the yield of C. acetobutylicum DG1 (pSPD5), we tried to knockout the $b k$ gene in the DG1 strain. Unfortunately, we never obtained any correct recombinant, suggesting that a strain of $C$. acetobutylicum producing only acetate from glucose might not be viable. Such a strain should oxidize NADH to produce $\mathrm{H}_{2}$ using the following electron transfer chain: NADH ferredoxin reductase, ferredoxin and hydrogenase. The Gibbs free energy for the production of $\mathrm{H}_{2}$ from NADH varies according to the following equation:

$\Delta G^{\prime}=\Delta G^{0^{\prime}}+R T \ln \frac{\left[\mathrm{NAD}^{+}\right]\left(p_{\mathrm{H}_{2}}\right)}{[\mathrm{NADH}]}$

with a $\Delta G^{0 \prime}$ value of $18.14 \mathrm{~kJ} / \mathrm{mol}$ (Stams, 1994). For a $\mathrm{NADH} / \mathrm{NAD}^{+}$ratio of 2 (which corresponds to the highest ratio ever described for $C$. acetobutylicum), $\Delta G^{\prime}$ is $\leqslant$ for a $\mathrm{H}_{2}$ partial pressure lower than $0.029 \mathrm{~atm}$, a value much lower than the $0.1 \mathrm{~atm}$ used in our anaerobic chamber for the selection of a DG1 $b k$ knockout strain.
Table 3

Specific rates of production and consumption and other parameters for continuous steady-state cultures of $C$. acetobutylicum DG1 (pSPD5) on glucose (I) and glycerol (II) at constant $\mathrm{pH} 6.5$ and dilution rate $(D)=0.05 \mathrm{~h}^{-1}$

\begin{tabular}{|c|c|c|}
\hline Glucose or glucose-glycerol input (mM) & I & II \\
\hline Glucose & 183 & 0 \\
\hline Glycerol & 0 & 327 \\
\hline Biomass $\left(\mathrm{g} \mathrm{L}^{-1}\right)$ & 1.6 & 0.71 \\
\hline YATP (g dry weight mol ${ }^{-1}$ ATP) & 2.7 & 4.96 \\
\hline \multicolumn{3}{|l|}{$\begin{array}{l}\text { Specific rate of formation or consumption } \\
\text { (mmol/h g dry weight) }\end{array}$} \\
\hline Glucose & 5.72 & 0 \\
\hline Glycerol & 0 & 23.02 \\
\hline Ethanol & 0.29 & 0 \\
\hline Acetate & 1.8 & 0.28 \\
\hline Butyrate & 4.00 & 3.16 \\
\hline Lactate & 0.81 & 0 \\
\hline 1,3-propanediol & 0 & 15.08 \\
\hline $\mathrm{CO}_{2}$ & 10.2 & 6.6 \\
\hline $\mathrm{H}_{2}$ & 11.3 & $<0.1$ \\
\hline $\mathrm{NAD}(\mathrm{P}) \mathrm{H}$ from $\mathrm{Fd}^{\mathrm{a}}$ & -1.17 & +7.22 \\
\hline $\mathrm{H}_{2} / \mathrm{CO}_{2}$ ratio & 1.12 & $<0.015$ \\
\hline Acetate/butyrate ratio & 0.456 & 0.088 \\
\hline $\mathrm{Y}_{1,3 \text {-propanediol }}(\mathrm{mol} / \mathrm{mol})$ & 0 & 0.64 \\
\hline
\end{tabular}

${ }^{\mathrm{a}} q_{\mathrm{NAD}(\mathrm{P}) \mathrm{H} \text { from Fd }}$ is the difference between the rate of $\mathrm{NAD}(\mathrm{P}) \mathrm{H}$ consumption and the rate of $\mathrm{NAD}(\mathrm{P}) \mathrm{H}$ formation in the central metabolism. On glucose $q_{\mathrm{NAD}(\mathrm{P}) \mathrm{H}}$ from Fd $=2 q_{\text {butyrate }}+2 q_{\text {ethanol }}+$ $q_{\text {lactate }}-2\left(q_{\text {glucose }}-8.8 \mu\right)$ and on glycerol $q_{\mathrm{NAD}(\mathrm{P}) \mathrm{H}}$ from $\mathrm{Fd}=$ $q_{\text {propanediol }}+2 q_{\text {butyrate }}+q_{\text {lactate }}-2\left(q_{\text {glycerol }}-q_{\text {propanediol }}-17 \mu\right)$.

\section{Metabolic ux analysis of C. acetobutylicum DG1 (pSPD5) grown on glucose or glycerol at $\mathrm{pH} 6.5$ in chemostat culture}

In order to better characterize the changes in electron flow introduced by the ability of $C$. acetobutylicum DG1 (pSPD5) to grow on glycerol and produce 1,3-propanediol, a metabolic flux analysis was done in chemostat culture grown on glucose or glycerol. The specific rates of substrate consumption and product formation for a constant total amount of carbon $(1100 \mathrm{mM})$ are shown in Table 3. The glucose-grown culture was acidogenic. The main products were butyrate, acetate and lactate. Part of the NADH produced during the glycolytic pathway was re-oxidized by the NADH-ferredoxin 
reductase $\left(q_{\mathrm{NAD(P)H} \mathrm{from} \mathrm{Fd}}<0\right)$ to yield reduced ferredoxin, which in turn was re-oxidized by the hydrogenase to produce $\mathrm{H}_{2}$. When glycerol was metabolized, 1,3propanediol became the major product. The specific rate of acid formation decreased, acetate and lactate being the most affected. The NADH produced during the glycolytic pathway was not sufficient for the formation of butyrate and 1,3-propanediol and most of the reduced ferredoxin produced by the pyruvate ferredoxin oxidoreductase was re-oxidized by the ferredoxin-NAD $(\mathrm{P})$ reductase(s) to produce $\mathrm{NAD}(\mathrm{P}) \mathrm{H}$ $\left(q_{\mathrm{NAD}(\mathrm{P}) \mathrm{H} \text { from Fd }}>0\right) . \mathrm{H}_{2}$ production was thereby very low.

\section{Fed-batch cultures of $C$. acetobutylicum DG1 (pSPD5) growing on glycerol}

Fed-batch cultures of the best $C$. acetobutylicum recombinant strain, DG1 (pSPD5), were carried-out in order to evaluate the potentialities of this strain. A high concentration of 1,3-propanediol $(1104 \mathrm{mM})$ was obtained in $47.5 \mathrm{~h}$ (Fig. 1), leading to a yield of $0.65 \mathrm{~mol}$ of 1,3-propanediol/mol of glycerol and a volumetric productivity of $1.8 \mathrm{~g} \mathrm{~L}^{-1} \mathrm{~h}^{-1}$. The total amount of glycerol consumed was $1797 \mathrm{mM}$. Butyrate $(193 \mathrm{mM})$, acetate $(67 \mathrm{mM})$ and lactate $(22 \mathrm{mM})$ were the other fermentation end-products obtained. Ethanol was not produced.

\section{Metabolic ux analysis and performances of $\mathrm{C}$. acetobutylicum DG1 (pSPD5) growing in continuous culture at different glycerol feed.}

In order to run a metabolic flux analysis and evaluate the performances of the DG1 (pSPD5) recombinant strain for the production of 1,3-propanediol, chemostat cultures $\left(D=0.05 \mathrm{~h}^{-1}\right)$ with different concentrations of glycerol $(325-1303 \mathrm{mM})$ in the feed tank were performed (Fig. 2).

The fluxes of glycerol consumption and 1,3-propanediol production follow the same pattern, i.e., a slight increase with the glycerol feed. On the other hand the

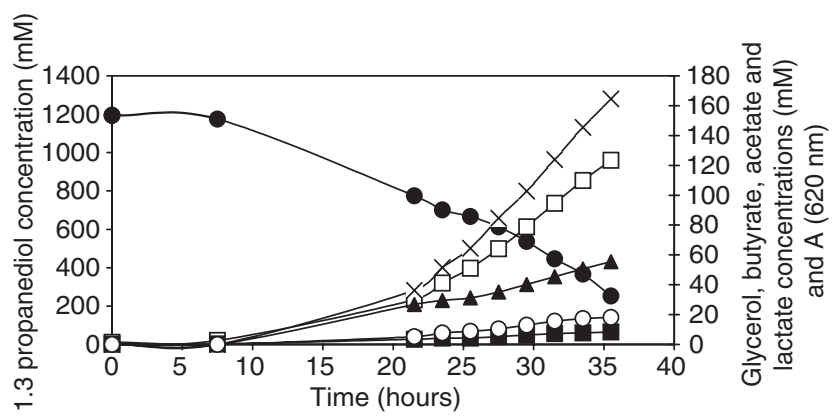

Fig. 1. Fermentation profile of a fed-batch culture of Clostridium acetobutylicum (DG1 (pSPD5) on glycerol, at pH 6.5. (ם) Absorbance

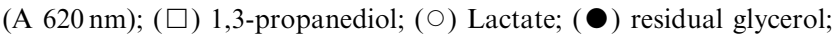
$(\mathbf{\Delta})$ acetate; and (x) butyrate.
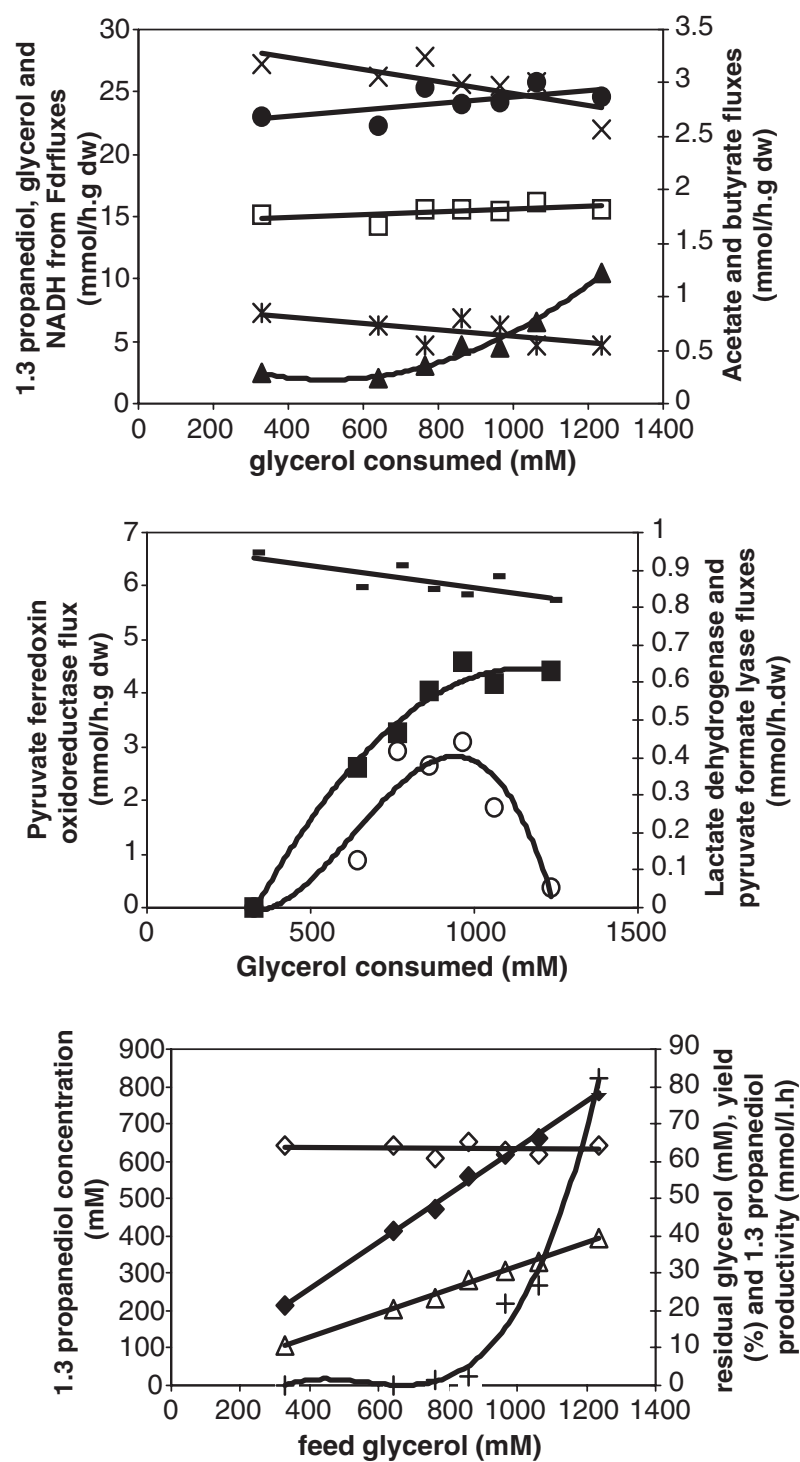

Fig. 2. Metabolic flux analysis from chemostat culture of the DG1 (pSPD5) with different concentrations of glycerol: (-) glycerol consumption flux; $(\square)$ 1,3-propanediol production flux; $(\boldsymbol{\Delta})$ acetate production flux; (x) butyrate production flux; ( $($ ) NADH from Fdr flux; (-) pyruvate ferredoxine oxidoreductase flux; (O) lactate dehydrogenase flux; (ם) pyruvate formate lyase flux; $(+)$ residual glycerol; $(\Delta)$ productivity; $(\diamond)$ yield; $(\diamond)$ 1,3-propanediol concentration.

butyrate flux slightly decrease and the flux of $\mathrm{NAD}(\mathrm{P}) \mathrm{H}$ production from reduced ferredoxin remained constant. The hydrogen flux was too low to be measured accurately. Major changes were observed in the fluxes around pyruvate. The flux in the pyruvate formate lyase (and the lactate dehydrogenase up to a certain glycerol concentration) increases with the glycerol feed while the pyruvate ferredoxin oxidoreductase flux slightly decrease.

The 1,3-propanediol yield was constant at a value of $0.64(\mathrm{~mol} / \mathrm{mol})$ while the 1,3-propanediol concentration and then the volumetric productivities increase with the 
glycerol feed to values of, respectively, $788 \mathrm{mM}$ and $3 \mathrm{~g} \mathrm{~L}^{-1} \mathrm{~h}^{-1}$. These continuous fermentations were carried out for six months without adding any erythromycin to the feed medium, showing the stability of the recombinant strain. The ability of $C$. acetobutylicum DG1 (pSPD5) to consume such a high concentration of glycerol might be due to an evolution of the strain during the six months of continuous cultivation. Therefore, new continuous fermentations were carried out, where substrate feed concentration was abruptly changed from 326 to $869 \mathrm{mM}$ and finally to $1303 \mathrm{mM}$. As the same steady state values $( \pm 10 \%)$ were obtained, it can be concluded that there was no measurable evolution of the strain during the six months of continuous culture.

\section{Chemostat culture of $\mathrm{C}$. acetobutylicum DG1 (pSPD5) growing on raw glycerol}

The possibility of producing 1,3-propanediol from an inexpensive source of glycerol was evaluated. Raw glycerol from a biodiesel production plant was used as substrate for continuous cultures of $C$. acetobutylicum DG1 (pSPD5). A $65 \% \mathrm{w} / \mathrm{v}$ grade raw glycerol was used at a dilution rate of $0.05 \mathrm{~h}^{-1}$. Results are shown in Table 4.

Glycerol consumption was around $100 \%$, whatever the type of glycerol used. 1,3-propanediol (394 mM), the major fermentation end-product, were obtained when $651 \mathrm{mM}$ of raw or commercial glycerol were used as carbon source; thus a molar yield of $0.61-0.64$ was achieved. Again, no significant differences between raw or purified glycerol fermentations were found regarding 1,3-propanediol volumetric productivity or 1,3-propanediol specific formation rate.

Table 4

Continuous cultures of $C$. acetobutylicum DG1 (pSPD5) on different types of glycerol $\left(D=0.05 \mathrm{~h}^{-1}, \mathrm{pH} 6.5,35^{\circ} \mathrm{C}\right)$

\begin{tabular}{lcc}
\hline Type of glycerol & $\begin{array}{l}\text { Commercial } \\
\text { glycerol }(87 \%)\end{array}$ & $\begin{array}{l}\text { Raw glycerol } \\
(65 \%)\end{array}$ \\
\hline Feed glycerol $(\mathrm{mM})$ & 642.8 & 636.3 \\
Residual glycerol $(\mathrm{mM})$ & 0 & 0 \\
Biomass $\left(\mathrm{g} \mathrm{L}^{-1}\right)$ & 1.44 & 1.64 \\
$1,3-\mathrm{Propanediol}(\mathrm{mM})$ & 411.3 & 391.6 \\
$\mathrm{Y}_{1,3-\mathrm{PD}}\left(\mathrm{mol} / \mathrm{mol}^{-1}\right.$ & 0.64 & 0.61 \\
$\mathrm{Q}_{1,3-\mathrm{PD}}\left(\mathrm{g} \mathrm{l}^{-1} \mathrm{~h}^{-1}\right)$ & 1.56 & 1.49 \\
$q_{1,3-\mathrm{PD}}\left(\mathrm{mmol} \mathrm{g}^{-1} \mathrm{~h}^{-1}\right)$ & 13.4 & 11.8
\end{tabular}

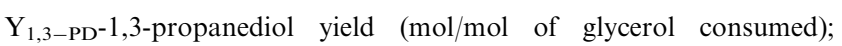
$\mathrm{Q}_{1,3-\mathrm{PD}}$-1,3-propanediol volumetric productivity; $q_{1,3-\mathrm{PD}^{-1,3-p r o p a-}}$ nediol specific formation rate.

For the carbon recovery calculation, carbon dioxide concentration was estimated from end-product concentrations based on Papoutsakis (1984).

\section{Discussion}

C. acetobutylicum cannot grow on glycerol as it cannot re-oxidize the excess of NADH generated in glycerol catabolism (Vasconcelos et al., 1994; Girbal et al., 1995). On the other hand, when the NADH consuming 1,3-propanediol pathway from C. butyricum was introduced in $C$. acetobutylicum growth on glycerol was achieved and 1,3-propanediol was the main fermentation product. C. acetobutylicum DG1 (pSPD5) was the most efficient recombinant strain for the conversion of glycerol to 1,3-propanediol. Our attempt to further increase the yield of 1,3-propanediol production by first knocking out the $b k$ gene of $C$. acetobutylicum DG1 has been so far unsuccessful, indicating that a strain of $C$. acetobutylicum producing only acetate from glucose is not viable. Such a strain has (i) to convert all the reducing power from NADH to reduced ferredoxin and (ii) to produce $4 \mathrm{~mol}$ of $\mathrm{H}_{2}$ and $2 \mathrm{~mol}$ of acetate per mol of glucose consumed. Our calculations demonstrate that there is a thermodynamic limitation to the production of $\mathrm{H}_{2}$ from NADH explaining why such a mutant could not be obtained.

A flux analysis of the DG1 (pSPD5) recombinant strain under glycerol feeding, shows that not only the $\mathrm{NADH}$ generated in glycolysis but also the NADH produced from reduced ferredoxin (itself produced from the decarboxylation of pyruvate) were re-oxidized mainly in the 1,3-propanediol pathway and at a lesser extent in the butyrate pathway. Due to this high reducing power flux from reduced ferredoxin to NADH, almost no reduced ferredoxin was used for hydrogen production, contrary to what was observed on glucose. A similar result was previously observed with $C$. acetobutylicum grown on glycerol-glucose mixtures and was associated with decreased activity of the in vitro NADH-erredoxin reductase and an increase activity of the in vitro ferredoxin NAD-reductase, while in vitro hydrogenase activity was slightly increased (Vasconcelos et al., 1994).

C. acetobutylicum DG1 (pSPD5) can produce $788 \mathrm{mM}$ of 1,3-propanediol in continuous cultures at relatively high yield $(0.64 \mathrm{~mol} / \mathrm{mol})$ and productivity $\left(3 \mathrm{~g} \mathrm{~L}^{-1} \mathrm{~h}^{-1}\right)$. This represents an almost two fold improvement in titer and productivity, when compared to C. butyricum (a natural 1,3-propanediol producer microorganism), that produces up to $460 \mathrm{mM}$ in similar conditions. Reimann et al. (1998) studied in chemostat culture the performances of the wild type strain and a "product tolerant mutant" of C. butyricum DSM 5431. In that work the maxima 1,3-propanediol concentrations achieved were $460 \mathrm{mM}$ with the mutant strain and $373 \mathrm{mM}$ with the wild type strain. C. acetobutylicum DG1 (pSPD5) clearly exhibits higher 1,3-propanediol titer than $C$. butyricum and the developed "product tolerant mutants" of C. butyricum DSM 5431. 
Table 5

Data on fed-batch cultures of $C$. butyricum VPI 3266 and $C$. acetobutylicum DG1 (pSPD5) $\left(D=0.05 \mathrm{~h}^{-1}, \mathrm{pH} 6.5,35^{\circ} \mathrm{C}\right)$

\begin{tabular}{lcc}
\hline & $\begin{array}{l}\text { C. butyricum } \\
\text { VPI3266 }\end{array}$ & $\begin{array}{l}\text { C. acetobutylicum } \\
\text { DG1 (pSPD5) }\end{array}$ \\
\hline $\begin{array}{l}\text { Maximum glycerol } \\
\text { consumed (mM) }\end{array}$ & 1238 & 1792 \\
$\begin{array}{l}\text { Maximum 1,3-PD } \\
\text { concentration (mM) }\end{array}$ & 854 & 1104 \\
$\begin{array}{l}\text { Butyrate (mM) } \\
\mathrm{Y}_{1,3-\mathrm{PD}}(\mathrm{mol} / \mathrm{mol})\end{array}$ & 170 & 193 \\
$\mathrm{Q}_{1,3-\mathrm{PD}}\left(\mathrm{g} \mathrm{L}^{-1} \mathrm{~h}^{-1}\right)$ & 0.69 & 0.65 \\
\hline
\end{tabular}

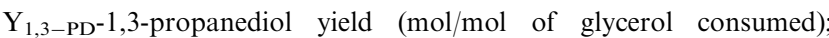
$\mathrm{Q}_{1,3-\mathrm{PD}}$-1,3-propanediol volumetric productivity.

${ }^{\text {a }}$ Saint-Amans et al. (1994).

In this work it was also shown that 1,3-propanediol concentration could be increased up to $1104 \mathrm{mM}$ when C. acetobutylicum DG1 (pSPD5) was grown in fed-batch cultures. The maximum 1,3-propanediol concentration achieved in fed-batch cultures of C. butyricum VPI 3266 was $854 \mathrm{mM}$ (Table 5). Abbad-Andaloussi et al. (1995) also studied the 1,3-propanediol production in batch cultures of a "product tolerant mutant" of $C$. butyricum DSM 5431. In that case, the mutant strain was able to produce $927 \mathrm{mM}$ of 1,3-propanediol in $85 \mathrm{~h}$.

C. acetobutylicum DG1 (pSPD5) also showed its ability to use inexpensive glycerol sources (raw glycerol) for biological 1,3-propanediol synthesis. When raw glycerol was used in continuous cultures, 1,3-propanediol production was not affected and the molar yield obtained was the same whether raw or commercial glycerol is used. With the constant growth of Biodiesel production in Europe and the current and future drop in raw glycerol prices, industrial production of 1,3propanediol with $C$. acetobutylicum DG1 (pSPD5) should be an attractive alternative to the glucose-based process developed by Dupont de Nemours.

\section{Acknowledgments}

This work was financially supported by the European Committee Fourth Project (contract no. QLK5-CT1999-01364) and the Agence de l'Environnement et de la Maitrise de l'Energie (contract no. 0001 027). M. González-Pajuelo was supported by PRAXIS XXI with a Ph.D. grant $(\mathrm{BD} / 16036 / 98)$.

\section{References}

Abbad-Andaloussi, S., Manginot-Durr, C., Amine, J., Petitdemange, E., Petitdemange, H., 1995. Isolation and characterization of Clostridium butyricum DSM 5431 mutants with increased resistance to 1,3-propanediol and altered production of acids. Appl. Environ. Microbiol. 61, 4413-4417.

Biebl, H., Marten, S., Hippe, H., Deckwer, W.D., 1992. Glycerol conversion to 1,3-propanediol by newly isolated clostridia. Appl. Microbiol. Biotechnol. 36, 592-597.

Cornillot, E., Soucaille, P., 1996. Solvent-forming genes in clostridia. Nature 380, 489.

Cornillot, E., Nair, R.V., Papoutsakis, E.T., Soucaille, P., 1997. The genes for butanol and acetone formation in Clostridium acetobutylicum ATCC 824 reside on a large plasmid whose loss leads to degeneration of the strain. J. Bacteriol. 179, 5442-5447.

Girbal, L., Croux, C., Vasconcelos, I., Soucaille, P., 1995. Metabolic shifts in Clostridium acetobutylicum. FEMS Microbiol. Rev. 17, 287-297.

Green, E.M., Boyton, Z.L., Harris, L.M., Rudolph, F.B., Papoutsakis, E.T., Bennett, G.N., 1996. Genetic manipulation of acid formation pathways by gene inactivation in Clostridium acetobutylicum ATCC 824. Microbiology 142, 2079-2086.

Harris, L.M., Desai, R.P., Welker, N.E., Papoutsakis, E.T., 2000. Characterisation of recombinant strains of the clostridium acetobutylicum butyrate kinase inactivation mutant: need for new phenomenological models for solventogenesis and butanol inhibition? Biotech. Bioeng. 67, 1-11.

Heyndrickx, M., de Vos, P., Vancanneyt, M., De Ley, J., 1991. The fermentation of glycerol by Clostridium butyricum LMG $1212 \mathrm{t}_{2}$ and $1213 \mathrm{t}_{1}$ and Clostridium pasteurianum LMG 3285. Appl. Microbiol. Biotechnol. 34, 637-642.

Humphreys, F.B., 1924. Formation of acrolein by Bacillus welchii. Infect. Dis. 35, 282-290.

Lin, E.C.C., Magasanik, B., 1960. The activation of glycerol dehydrogenase from Aerobacter aerogenes by monovalent cations. J. Biol. Chem. 235, 1820-1823.

Luers, F., Seyfried, M., Daniel, R., Gottschalk, G., 1997. Glycerol conversion to 1,3-propanediol by Clostridium pasteurianum: cloning and expression of the gene encoding 1,3-propanediol dehydrogenase. FEMS Microbiol. Lett. 154, 337-345.

Mermelstein, L.D., Papoutsakis, E.T., 1993. In vivo methylation in Escherichia coli by Bacillus subtilis phage F 3 T methyltransferase to protect plasmids from restriction upon transformation of Clostridium acetobutylicum ATCC 824. Appl. Environ. Microbiol. 59, 1077-1081

Mermelstein, L.D., Welker, N.E., Bennett, G.G., Papoutsakis, E.T., 1992. Expression of cloned homologous fermentative genes in Clostridium acetobutylicum ATCC 824. Biotechnology 10, 190-195.

Miller, H., 2000. Major fiber producers hop on corterra bandwagon. Int. Fiber J. 15, 14-16.

Nair, R., 1995. Molecular characterisation and regulation of a multifunctional aldehyde/alcohol dehydrogenase gene from and its use for genetic engineering of Clostridium acetobutylicum ATCC 824. Ph.D., Northwestern University, Evanston, IL, USA.

Papoutsakis, E.T., 1984. Equations and calculations for fermentations of butyric acid bacteria. Biotechnol. Bioeng. 26, 174-187.

Raynaud, C., Sarçabal, P., Meynial-Salles, I., Croux, C., Soucaille, P., 2003. Molecular characterization of the 1,3-propanediol operon of Clostridium butyricum encoding a novel coenzyme B12 independent glycerol dehydratase and a 1,3 propanediol dehydrogenase. Proc. Natl. Acad. Sci. 100, 5010-5015.

Reimann, A., Abbad-Andaloussi, S., Biebl, H., Petitdemange, H., 1998. 1,3-Propanediol formation with product-tolerant mutants of Clostridium butyricum DSM 5431 in continuous culture: productivity, carbon and electron flow. J. Appl. Microbiol. 84, $1125-1130$

Ruch, D., Karibian, D., Karnovsky, M., Magasanik, B., 1957. Pathways of glycerol dissimilation in two strains of Aerobacter 
aerogenes: enzymatic and tracer studies. J. Biol. Chem. 226, 891-899.

Rudie, R., 2000. Cargill dow sows seeds of future fibers; will build \$ 300 million PLA polymer plant. Int. Fiber J. $15,8-12$.

Saint-Amans, S., Perlot, P., Goma, G., Soucaille, P., 1994. High production of 1,3-propanediol from glycerol by Clostridium butyricum VPI 3266 in a simply controlled fed-batch system. Biotech. Lett. 16, 831-836.

Saint-Amans, S., Girbal, L., Andrade, J., Ahrens, K., Soucaille, P., 2001. Regulation of carbon and electron flow in Clostridium butyricum VPI 3266 grown on glucose-glycerol mixtures. J. Bacteriol. 183, 1748-1754.

Schütz, H., Radler, F., 1984. Anaerobic reduction of glycerol to propanediol-1,3 by Lactobacillus brevis and Lactobacillus buchneri. System Appl. Microbiol. 5, 169-178.
Sobolov, M., Smiley, K.L., 1959. Metabolism of glycerol by an acrolein-forming lactobacillus. J. Bacteriol. 79, 261-266.

Stams, A.J.M., 1994. Metabolic interactions between anaerobic bacteria in methanogenic environments. Anton. Leeuw. 66, 271-294.

Streekstra, H., Teixeira de Mattos, M.J., Neijssel, O.M., Tempest, D.W., 1987. Overflow metabolism during anaerobic growth of Klebsiella aerogenes NCTC 418 on glycerol and dihydroxyacetone in chemostat culture. Arch. Microbiol. 147, 268-275.

Sullivan, C.J., 1993. Propanediols, in Ullmann's Encyclopedia of industrial Chemistry.

Vasconcelos, I., Girbal, L., Soucaille, P., 1994. Regulation of carbon and electron flow in Clostridium acetobutylicum grown in chemostat culture at neutral $\mathrm{pH}$ on mixtures of glucose and glycerol. J. Bacteriol. 176, 1443-1450. 